\title{
Genetic, familial and environmental correlates of asthma among early adolescents in Sri Lanka: a case control study
}

Manjula Nishanthi Danansuriya ${ }^{1 *}$, Lalini C Rajapaksa ${ }^{2}$ and Anura Weerasinghe ${ }^{3}$

\begin{abstract}
Background: Despite advances in management, the mortality and morbidity due to asthma are increasing globally. Identification of specific correlates in the local context is useful in disease management. The objective of this study was to estimate the prevalence and to describe selected correlates of asthma among12-14 year old school children in a district in Sri Lanka.
\end{abstract}

Method: A school based cross-sectional study was conducted using a self administered questionnaire. Multi-staged stratified cluster sampling was used to select 42 classes in grades 7, 8 and 9. "Current asthma" (CA)(case) was defined as 'having Physician Diagnosed Asthma (PDA) and having had wheezing during the previous 12 months'. For each case, two healthy controls were selected from the same class to assess correlates. Information on correlates was collected by trained field midwives during home visits. Backward stepwise logistic regression model was used for analysis of correlates. Skin Prick Testing was carried out among asthmatics together with their healthy siblings using standard extracts of House Dust Mite (HDM), cockroach and Blomia. Ethical clearance was obtained from Ethical Review Committee, Faculty of Medicine, Colombo.

Results: Out of 1483 subjects participated, 753 were females (50.8\%). The prevalence rates for current wheezing (CW), ever wheezing (EW), current asthma (CA), and physician diagnosed asthma (PDA) were 16.7\%, 19.4\%, 10.7\% and $14.5 \%$ respectively. A total of 158 CA cases were identified. Information on correlates of asthma was collected for 145 CA cases (97.9\%) and for 285 controls (96.6\%). The unconfounded predictors of having CA among adolescents in the present sample were; only child in the family $(\mathrm{OR}=4.2,95 \% \mathrm{Cl}: 1.7-9.9)$; first born of the family $(\mathrm{OR}=2.695 \% \mathrm{Cl}: 1.3-5.2)$; presence of allergic rhinitis $(\mathrm{OR}=2.7,95 \% \mathrm{Cl}: 1.6-4.6)$; family history of asthma $(\mathrm{OR}=1.8,95 \% \mathrm{Cl}: 1.1-3.2)$; family history of allergic rhinitis $(\mathrm{OR}=1.9,95 \% \mathrm{Cl}: 1.1-3.2)$; family history of eczema $(\mathrm{OR}=1.8,95 \% \mathrm{Cl}: 1.0-3.2)$. Higher risk of sensitization to cockroach, HDM and Blomia was seen among asthmatics compared to healthy siblings.

Conclusion: A significant proportion of students reported to have asthma. Atopy and other genetic and environmental correlates should be considered as important correlates in asthma management among early adolescents in Sri Lanka.

Keywords: Asthma, Atopy, Adolescents, Sri Lanka, Skin prick test

\footnotetext{
* Correspondence: manju114c@yahoo.com

'Adolescent Health Unit Family Health Bureau Ministry of Health 231, De Saram Place, Colombo 10, Sri Lanka

Full list of author information is available at the end of the article
} 


\section{Background}

Asthma is a syndrome characterized by airflow obstruction that varies spontaneously and with treatment [1]. Asthma is considered as the most common chronic illness in childhood, and despite advances in management; asthma morbidity and mortality are increasing globally [2,3]. The International Study on Asthma and Allergies in Childhood (ISAAC) revealed increasing prevalence of asthma in children and adolescents ranging from $0.8 \%$ to $32.6 \%[4,5]$.

The causality of asthma has been identified as a priority area in the field of asthma research [6]. It is presumed to be multi factorial [7]. The presence of family history of atopy, allergens, exposure to tobacco smoke, irritants and air pollution are considered as significant risk factors [2].

Asthma is a public health problem in Sri Lanka $[8,9]$. The prevalence of asthma among 5-11 year old children varies between $13 \%-25 \%[10,11]$ and asthma has been recognized as a major cause for school absence among primary school children [12]. The disease burden and risk factors for asthma in childhood have been studied in detail $[10,11,13-16]$. Information on impact of asthma on adolescents in Sri Lankan context is limited.

Adolescence is a period of transition with physical, mental and social changes. Not only the disease of asthma itself but its management also affects adolescents in specific ways, different to children and adults. Therefore asthma in adolescence should be given a special consideration and need to be studied extensively to support better clinical management. This is a part of a larger study which looked in to asthma burden, correlates and effects of asthma on the quality of life among early adolescents in an industrially developing setting like Sri Lanka.

The aims of the present study are to provide estimates on the prevalence of asthma and wheezing and to describe selected familial, genetic and environmental correlates of asthma among 12-14 year old school children in a selected district in Sri Lanka.

\section{Methods}

The study was conducted in Gampaha district in the Western Province of Sri Lanka. The selected district ranges from highly urbanized, semi urbanized to rural areas and consists of a population of school children with diverse socioeconomic and ethnic composition. Gampaha is the second most populated district in Sri Lanka with a population of 2,294,641 as per the latest 2012 census [17]. The particular district was selected purposively considering above factors and the feasibility of data collection.

School children in grades 7, 8 and 9 in Sinhala medium schools were included. Physically or mentally handicapped children were excluded. Sample size for the prevalence study was calculated based on an expected prevalence of $20 \%$ and a precision level of $5 \%$. The multi-staged stratified cluster sampling method was used. The original study which assessed prevalence, correlates of asthma among adolescents and their quality of life, employed a sample of 1512 students. The sample consists of 42 clusters and a cluster represented a class with 36 students. The students were given a self administered questionnaire with the questions on asthma and wheezing prepared based on the ISAAC Tool. Additional visits to the schools were made in instances where absentees exceeded $15 \%$ on the day of data collection.

Case control methodology was used to examine the correlates of asthma. Sample size for case control study was calculated based on the exposure as positive family history of asthma assuming $80 \%$ power with the use of 2 -sided tests and an alpha level of 0.05 . The non exposure rate for the family history of asthma was predicted to be $2 \%$ based on the adjusted odds ratio of 3.8 [14]. With 2:1 control matching, the number of cases and controls were 151 and 302 respectively.

Students reported to have Physician Diagnosed Asthma (PDA) and having had asthma symptoms (wheezing) during the previous 12 months for the self administered questionnaire, were categorized as Current Asthma (CA) and were considered as cases $(n=158)$ for the case control component. Students living outside the selected district and/or staying in a hostel/orphanage were excluded due to difficulties in collecting information.

For each identified student with Current Asthma (case), two "healthy" controls were selected from the same class according to the student's self-response. We included a question inquiring presence of any chronic illness requiring long term medication or clinic follow up during the preceding six months period. Students answered negatively, were categorized as "healthy". The two "healthy" students placed in the class register next to the "case" were taken as two controls. The student's self-reported "healthy" and "asthma" status were further verified with the parent/guardian during home visits. We trained Public Health Midwives (PHM) as data collectors with a locally developed, pre tested interviewer administered "Home visit report" to collect information on correlates on asthma of adolescents during home visits.

Working definitions for selected correlates for data collection were constructed. Low birth weight was defined as a birth weight less than 2500 grams as recorded in the child health development record. Gestational period was determined as pre term, term and post term based on the records in the child health developmental record. Exposure to traffic was assessed by the proximity of the permanent residence to the closest main road. Houses situated closer to the main road (with heavy 
vehicular traffic) were considered as exposed to traffic. Presence of more than two persons in the student's bedroom was considered as exposure to bedroom overcrowding [18]. Exposure to smoke due to biomass combustion was considered "positive" if the principal source of fuel was firewood and the cooking place/hearth was situated inside the house and absence of a chimney above the cooking place/hearth [19].

Exposure to irritant smoke (mosquito coils/joysticks) was taken as positive if those were being used regularly (more than 3-4 days a week) in the house. If the respondent described presence of cockroaches as "a few" or "a lot", it was considered as positive exposure to cockroaches. With regard to cockroaches, the presence or absence of cockroaches was considered as more important than the number, therefore it was taken as exposed even if there were "a few" cockroaches according to the informant. Positive current exposure to pets was defined according to the presence of either cat or a dog at home at present. The presence of dampness in the bedroom was considered as a proxy indicator on exposure to mould in bedroom. The PHMs were asked to observe the place/room where the student used to sleep and inspect for the presence of a leaking roof/damp walls/ damaged walls or plaster of wall/visible mould growth on wall/roof. If any of the above were present, they were taken as positive exposure to mould [18].

Biological parents and siblings were regarded as the immediate family in assessing the family history. Family history of rhinitis was defined by a positive answer to the question "Do you have any family member/s suffering from runny or stuffy nose, itchy red eyes with sneezing especially in the morning?" A family history of other allergies was considered positive in the presence of a family member with allergy towards drugs/food/or any other thing. Any passive exposure to tobacco smoke at present or during last one year period was considered as current exposure to tobacco smoke.

Female sex, having more than one child, later parity, term birth, appropriate birth weight, negative exposure to risk factors was taken as reference category in univariate and multivariate analysis.

Odds ratios were used for the assessment of unadjusted associations among categorical variables in the univariate analysis. The multivariate analysis was carried out to determine the best predictors of current asthma using a logistic regression model (backward stepwise). The dependant variable was coded as 0 and 1 for controls and current asthma cases respectively. All independent factors were included as categorical variables. The correlates that have been identified as predictors/ risk factors by the previous researchers were entered to the model irrespective of their level of significance, demonstrated in the univariate analysis.
Variables entered to the model included, sex of the student; being the only child, being the first born of the family, presence of low birth weight, born as a pre term baby, having breast fed exclusively for 4 months, presence of allergic rhinitis or other allergies, presence of overweight, exposure to traffic smoke, or bed room overcrowding, or bio mass combustion or irritant smoke; exposure to cockroaches, presence of visible mould in the bed room, presence of current or past exposure to pets, presence of family history of asthma, allergy, eczema or allergic rhinitis and presence of present or past exposure to tobacco smoke. For the regression model, probability was fixed for entry at 0.05 level and removed at 0.1 significance level. Final model included 403 cases $(93.7 \%)$ and the chi square was $96.0(\mathrm{p}=0.000)$.

The Skin Prick Testing (SPT) was done to identify causative allergens in the atopic individuals using three common allergens; cockroach (blattella germanica), house dust mite (dermatophagoides pteronyssinus) and storage mite (blomia) standardized extracts from Stallergenes (France). Histamine (0.1\%) and physiologic saline were used as controls.

Inclusion criteria for skin prick testing were; CA cases with a healthy sibling aged + or -5 years. If the particular sibling had current asthma or asthma ever, they were excluded. Students living in a children's home/orphanage were also excluded. Paired $t$ test and McNemar's test for difference between related samples were used as appropriate for the analysis.

\section{Results and discussion}

The present study was carried out as a part of larger study aimed to estimate the prevalence of asthma, identify its correlates and to describe its effect on the quality of life among 12-14 year old school children. Multi stage cluster sampling method was used to select the sample for the prevalence survey. This analysis aims to provide with evidence on asthma prevalence and the correlates among early adolescents relevant to a developing country like Sri Lanka in order to support better clinical management of asthma among adolescents.

A total of 1483 students were enrolled from 42 clusters (classes). Majority were Sinhalese (95.1\%) due to the inclusion of only Sinhala medium schools and the predominant Sinhala population in the district. There were 753 females $(50.8 \%)$. The mean age was 13.38 years $(\mathrm{SD}=0.8)$. Of the students $84 \%(\mathrm{n}=1251)$ reported absence of a chronic disease (Healthy) while $15.5 \%(n=232)$ answered affirmatively.

The self reported prevalence rates were current wheezing $(\mathrm{CW})$, ever wheezing (EW), current asthma (CA) and physician diagnosed asthma (PDA) were 16.7\% 19.4\% $10.7 \%$ and $14.5 \%$ respectively (Table 1 ). Higher prevalence of CW, EW, CA and PDA was observed among males 
Table 1 The prevalence of asthma and wheezing

\begin{tabular}{|c|c|c|c|}
\hline & $\mathrm{N}$ & Prevalence \% & $\begin{array}{l}95 \% \text { confidence } \\
\text { interval }\end{array}$ \\
\hline Current wheezing (CW) & 248 & 16.7 & 14.8-18.6 \\
\hline Ever wheezing (EW) & 288 & 19.4 & $17.3-21.3$ \\
\hline Current asthma (CA) & 158 & 10.7 & $8.9-14.5$ \\
\hline $\begin{array}{l}\text { Physician diagnosed } \\
\text { asthma (PDA) }\end{array}$ & 214 & 14.5 & $12.8-16.4$ \\
\hline
\end{tabular}

$(\mathrm{p}<0.05)$. Nearly $11 \%$ of students had exercise induced wheezing (CI, 9.3-12.5). These estimates were based on the questions adopted from the ISAAC tool, designed for population-based research and has been validated locally $[10,13,14,20-22]$. The definition for CA was constructed according to literature and expert opinion. Gampaha can be considered as a district with satisfactory health facilities and it is unlikely that an adolescent living with asthma, in Gampaha district would not have a diagnosis by a physician. The reported CA prevalence is lower compared to Karunasekara et al. (2003) which showed an asthma

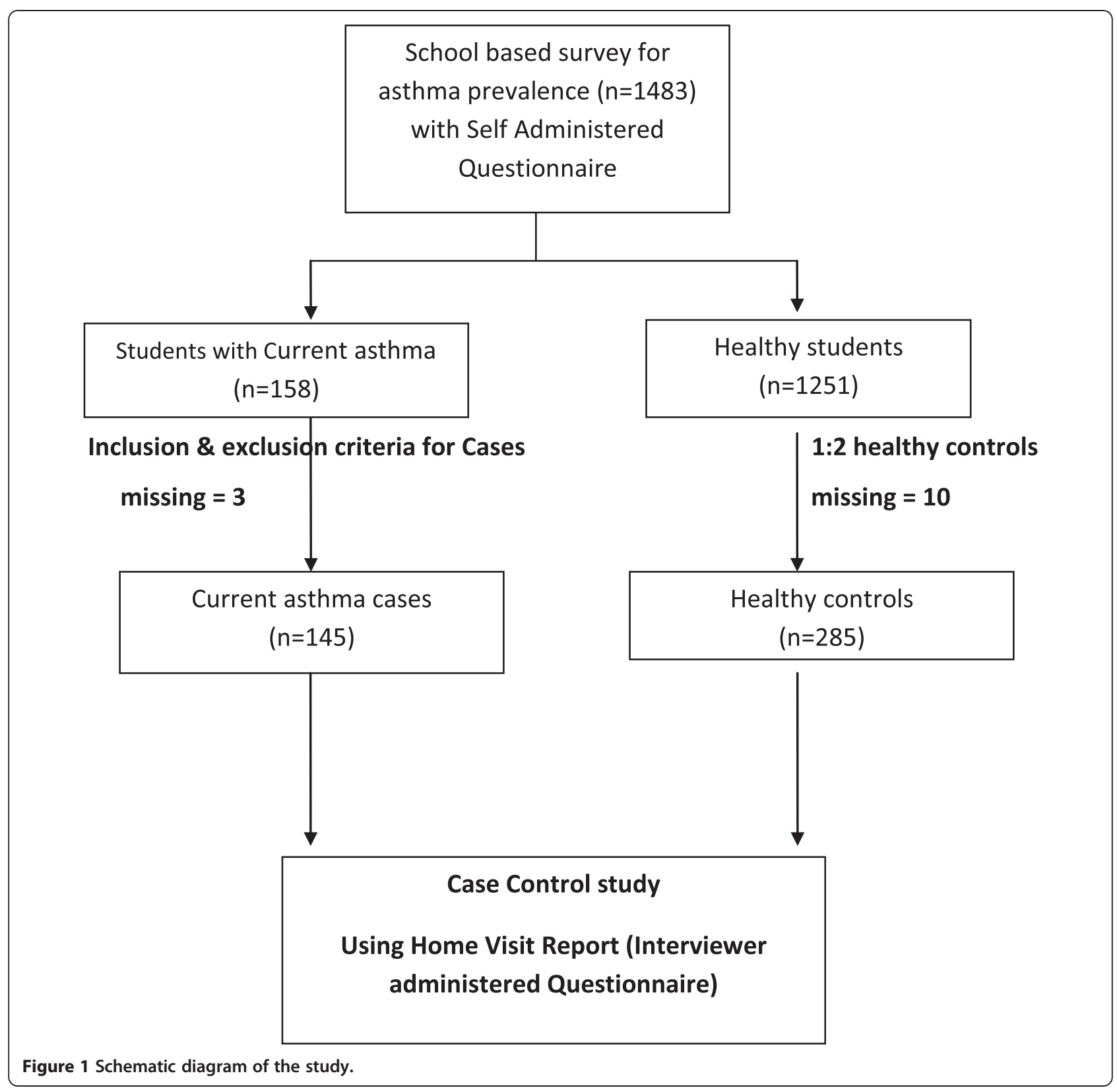


Table 2 Socio demographic information of asthma cases and healthy controls

\begin{tabular}{|c|c|c|c|c|c|}
\hline \multirow[t]{2}{*}{ Variable } & \multicolumn{2}{|c|}{ Case $(\mathrm{N}=145)$} & \multicolumn{2}{|c|}{ Control $(\mathrm{N}=285)$} & \multirow[t]{2}{*}{ Unadjusted OR $(95 \% \mathrm{Cl}$} \\
\hline & No & $\%$ & No & $\%$ & \\
\hline \multicolumn{6}{|l|}{ Sex } \\
\hline Male & 92 & 63.4 & 155 & 54.4 & $0.6(0.4-1.0)$ \\
\hline \$Female & 53 & 36.6 & 130 & 45.6 & \\
\hline \multicolumn{6}{|l|}{ Number of children } \\
\hline One child & 23 & 15.9 & 17 & 6.0 & $2.9^{*}(1.5-5.7)$ \\
\hline \$More than one child & 122 & 84.1 & 268 & 94.0 & \\
\hline \multicolumn{6}{|l|}{ Birth order } \\
\hline First born & 85 & 58.6 & 126 & 44.2 & $1.7^{*}(1.1-2.6)$ \\
\hline \$Later born & 60 & 41.3 & 159 & 55.7 & \\
\hline \multicolumn{6}{|c|}{ Mother's educational level } \\
\hline Up to secondary level & 75 & 51.7 & 140 & 49.1 & $1.1(0.7-1.6)$ \\
\hline \$Above secondary & 69 & 47.5 & 143 & 50.1 & \\
\hline Don't know & 1 & 0.6 & 2 & 0.7 & \\
\hline
\end{tabular}

${ }^{*}$ significant at $p<0.05$ level $\left(2\right.$ tailed) ${ }^{\$}$-reference category.

prevalence of $23 \%$ and also to $17 \%$, reported by Amarasekara et al. (2010) [10,11]. It is important to note that the differences in case definitions used, age groups selected and sample selection could have influenced the disparity in results. The $\mathrm{CW}$ prevalence rates are within the rates reported by other local studies including ISAAC -Phase III [22]. The CW prevalence falls within the rates reported by the international ISAAC study which ranged from $5.1 \%$ to $37.6 \%$ [23]. Regional countries have reported lower rates as $6.4 \%$ in India and $11.7 \%$ in Pakistan and 5.2\% in Indonesia which again can be explained as differences in age group selected and methodology used [23].

With regard to case control component of the study, of the 158 reported CA cases, eight students did not fulfil the selection criteria and two were excluded as their caregiver did not confirm the CA status. Midwives were able to collect information for 145 cases only $(1.8 \%$ missing). Of the 300 controls, five students were excluded as their "healthy" status did not corroborate with the

Table 3 Results of the logistic regression analysis of selected correlates of asthma

\begin{tabular}{lll}
\hline Variable & $\begin{array}{l}\text { Unadjusted OR } \\
\mathbf{( 9 5 \% ~ C I )}\end{array}$ & $\begin{array}{l}\text { Adjusted OR } \\
\mathbf{( 9 5 \% ~ C l )}\end{array}$ \\
\hline Being the only child & $2.9(1.5-5.7)$ & $4.2(1.7-9.9)$ \\
Being the first born & $1.7(1.1-2.6)$ & $2.6(1.3-5.2)$ \\
Presence of allergic rhinitis & $2.71(1.7-4.1)$ & $2.8(1.6-4.6)$ \\
Presence of family history of asthma & $2.5(1.6-3.8)$ & $1.8(1.1-3.2)$ \\
$\begin{array}{l}\text { Presence of family history of allergic } \\
\text { rhinitis }\end{array}$ & $2.1(1.4-3.1)$ & $1.9(1.1-3.2)$ \\
Presence of family history of eczema & $1.8(1.1-3.1)$ & $1.8(1.0-3.2)$ \\
\hline
\end{tabular}

*Significant at $p<0.05$ level ( 2 tailed) $N=403$ (93.7\%). caregiver and midwives were unable to collect information from ten healthy controls (3.3\% missing) (Figure 1). The final analysis was based on 145 CA cases (97.9\%) and 285 healthy controls (96.6\%) (Table 2).

The case control sample $(n=430)$ comprised of 178 females (41.8\%) while our original sample had 50.8\%. There were no significant differences among the ethnic composition between the two samples where 93\% were Sinhalese in the sub sample compared to $95 \%$ in the original sample which was used to assess prevalence rates. In the subsample, $28.5 \%$ were living in urban areas compared to $25 \%$ in the original survey sample.

The univariate analysis revealed that born as the first child, only child, bed room overcrowding, exposure to

Table 4 Paired analysis of atopy to allergens among cases and healthy sibling controls

\begin{tabular}{|c|c|c|c|c|}
\hline \multirow[b]{2}{*}{ Cases (\%) } & \multicolumn{2}{|c|}{ Controls (\%) } & \multirow[b]{2}{*}{ Total } & \multirow{2}{*}{$\begin{array}{l}\text { Unadjusted odds } \\
\text { ratio }(95 \% \mathrm{Cl})\end{array}$} \\
\hline & Positive & Negative & & \\
\hline \multicolumn{5}{|l|}{ Blomia } \\
\hline Positive & $4(14.8)$ & $23(85.2)$ & $27(100.0)$ & $\mathrm{OR}=11.5(2.7-48.7)$ \\
\hline \$Negative & $2(6.1)$ & $31(93.9)$ & $33(100.0)$ & \\
\hline Total & $6(10.0)$ & $54(90.0)$ & $60(100.0)$ & \\
\hline \multicolumn{5}{|c|}{ House dust mite } \\
\hline Positive & $3(10.3)$ & $26(89.7)$ & $29(100.0)$ & $\mathrm{OR}=13.0(3.1-54.7)$ \\
\hline \$Negative & $2(6.5)$ & $29(93.5)$ & $31(100.0)$ & \\
\hline Total & $5(8.3)$ & $55(91.7)$ & $60(100.0)$ & \\
\hline \multicolumn{5}{|l|}{ Cockroach } \\
\hline Positive & $4(11.1)$ & $32(88.9)$ & $36(100.0)$ & $\mathrm{OR}=5.3(2.2-12.7)$ \\
\hline \$Negative & $6(25.0)$ & $18(75.0)$ & $24(100.0)$ & \\
\hline Total & $10(16.7)$ & $50(83.3)$ & $60(100.0)$ & \\
\hline
\end{tabular}

$\mathrm{N}=60$ *Significant at $\mathrm{p}<0.05$ level ( 2 tailed) ${ }^{\text {s }}$-reference category. 
cockroaches, presence of allergic rhinitis and other allergies, family history of asthma, allergic rhinitis and eczema were significantly associated with current asthma status of these early adolescents (Table 3). However, there was no significant association of male sex [24], low birth weight [25], pre term birth [26], exclusive breast feeding for 4 months [14], presence of overweight [27] exposure to traffic smoke or bed room overcrowding $[14,28,29]$ or exposure to mould in the bed room with current asthma in the present univariate analysis. Past or present exposure to pets [30], family history of other allergies; present or past exposure to tobacco smoke [31] also failed to show significant relationships with current asthma status as per the univariate analysis. The observed variances could be due to true variances as per the global evidence which shows a diverse picture with regard to associations between asthma and exposures mentioned. It also could be due to variations in the operational definitions used, methods of data collection, recall bias, etc.

Of the variables selected for the regression model, six variables were identified as significant correlates for current asthma in this sample (Table 3). The unconfounded predictors for having current asthma among early adolescents in the present sample were; being the only child in the family $(\mathrm{OR}=4.2,95 \% \mathrm{CI}: 1.7-9.9)$; being the first born ( $\mathrm{OR}=2.7 \% \mathrm{CI}: 1.3-5.2)$; presence of allergic rhinitis $(\mathrm{OR}=2.7,95 \% \mathrm{CI}$ : 1.6-4.6); positive family history of asthma (OR $=1.8,95 \%$ CI: 1.1-3.2); positive family history of allergic rhinitis $(\mathrm{OR}=1.9,95 \% \mathrm{CI}$ : 1.1-3.2); positive family history of eczema (OR $=1.8,95 \%$ CI: 1.0-3.2).

The present study failed to reveal a significant association between CA and exposure to tobacco smoke as with other studies [13]. The true relationship between smoking and asthma may be masked by a change in behavior following diagnosis of asthma. Our findings did not show any increased risk of CA with exposure to traffic smoke or bio mass combustion or living in urban area. This may be due to that adolescents are likely to spend most of their time outside home environment. The association with pet exposure and asthma was difficult to explore using a cross sectional design and moreover, families with a history of atopy may avoid keeping pets $[14,21]$.

Of the 158 reported CA cases, 94 were eligible for skin prick testing (SPT). Of them 60 students-sibling pairs participated for SPT (64\% response rate). There were no statistically significant differences observed between the participants and non respondents in basic sociodemographic and other characteristics related to asthma or atopic conditions. Majority of the asthmatic cases (78.7\%) were atopic compared to $16.4 \%$ among healthy siblings $(\mathrm{p}=0.001)$. Cockroach was the commonest individual allergen, to which asthmatics were sensitive of
(60.7\%). It could be expected as cockroaches, are common in domestic environment, with a high probability of exposure to cockroach excreta. The present study found that students with current asthma were having 5.3 (95\% CI: 2.2-12.6), 13 (95\% CI: 3.8-54.7) and 11.5 (95\% CI: 2.7-48.7), times higher risk of atopy towards cockroach, HDM and Blomia respectively compared to their healthy siblings. The wide confidence interval is a result of the relatively small sample size (Table 4). HDM and Cockroach have been identified as the commonest indoor allergens associated with CA in other local studies as well $[32,33]$.

\section{Conclusion}

Asthma is found to be a common health problem among the 12-14 year old school children. The reported prevalence rates for current wheezing, current asthma and physician diagnosed asthma were $16.7 \%, 10.7 \%$ and $14.5 \%$ respectively. This study highlights atopy and other genetic and environmental correlates among early adolescents as important factors to be considered in asthma management.

\section{Abbreviations}

CA: Current asthma; CW: Current wheezing; EW: Ever wheezing; HDM: House dust mite; PDA: Physician diagnosed asthma; SPT: Skin prick testing; ISAAC: International study on asthma and allergies in childhood; OR: Odds ratio.

\section{Competing interests}

All authors declare that they have no competing interests.

\section{Authors' contributions}

MND contributed in designing the study, preparing the proposal, data collection, data analysis and wrote the manuscript. LCR participated in design phase, data analysis, writing the manuscript and critically revised the manuscript. AW contributed in designing study, data collection and writing the manuscript. All authors read and approved the manuscript.

\section{Acknowledgements}

We are grateful for all the children, their parents, teachers, volunteered for this research, and to education and health officials for their immense support.

\section{Author details}

${ }^{1}$ Adolescent Health Unit Family Health Bureau Ministry of Health 231, De Saram Place, Colombo 10, Sri Lanka. ${ }^{2}$ Department of Community Medicine, Faculty of Medicine, University of Colombo, Colombo, Sri Lanka. ${ }^{3}$ Medicine and Immunology Dr Neville Fernando Teaching Hospital, South Asian Institute of Medicine and Technology, Malabe, Sri Lanka.

Received: 15 May 2014 Accepted: 30 March 2015

Published online: 16 June 2015

\section{References}

1. Hargreave FE, Nair P. The definition and diagnosis of Asthma. Clin Exp Allergy. 2009;39(11):1652-8.

2. WHO. WHO fact sheet - No 307. Geneva: World Health Organization; 2008

3. Anandan C, Nurmatov U, Van Schayck OCP, Sheikh A. Is the prevalence of asthma declining? systematic review of epidemiological studies. Allergy. 2010;65(2):152-67.

4. Lai CKW, Beasley R, Crane J, Foliaki S, Shah J, Weiland S, et al. Global variation in the prevalence and severity of asthma symptoms: phase three of the international study of asthma and allergies in childhood (ISAAC). Thorax. 2009;64(6):476-83. 
5. Wong GWK, Leung TF, Ko FWS. Changing prevalence of allergic diseases in the Asia-Pacific region. Allergy Asthma Immunol Res. 2013;5(5):251-7.

6. Masoli M, Fabian D, Holt S, Beasley R. Global burden of asthm: executive summary of the GINA dissemination committee report. Allergy. 2004;59(5):469-78.

7. Strachan D, Anderson H, Limb E, O'Neill A, Wells N. A national survey of asthma prevalence, severity, and treatment in Great Britain. Arch Dis Child. 1994;70:174-8.

8. Ministry of Health. Annual Health Bulletin. Sri Lanka: Department of Health Services; 2006

9. Ministry of Health. Annual Health Bulletin. Sri Lanka: Department of Health Services; 2007.

10. Karunasekera KAW, Perera KPJ, Perera MTPR, Abeynarayana J. Prevalence of asthma and atopic symptoms in children aged 5-11years. Sri Lanka Journal of Child Health. 2003;32:11-4.

11. Amarasekera N, Gunawardena N, de Silva N, Weerasinghe A. Prevalence of childhood atopic diseases in the Western Province of Sri Lanka. Ceylon Med J. 2010;55(1):5-8.

12. Pathmeswaran A, Jayatissa R, Samarasinghe S, Fernando A, Thattil RO, de Silva NR. Health Status of primary school children in Sri Lanka. Ceylon Med J. 2005;50(2):46-50.

13. Karunasekara K, Fernando A, Perera K. Community prevalence of childhood asthma and atopy. In: 9th Annual scientific congress. Colombo: Proceedings of Sri Lanka College of Paediatricians,24th-27th August 2005; 2005.

14. Karunasekara K, Perera K, Perera M, Abeynarayana J. Genetic and environmental risk for asthma in children aged 5-11 years. Sri Lanka Journal of Child Health. 2005;34:79-83.

15. Karunasekara KAW, Fernando AD, Jayasinghe CY. Impact of corticosteroid therapy on lifestyles in asthmatic children from Sri Lanka. Indian Paediatrics. 2010;47:433-5.

16. Bandaranayake $G$, Wijesuriya $A$. A descriptive study on usage of inhaled steroids in children. Sri Lanka Journal of Child Health. 2010;39(4):128-32.

17. Population and Housing, Department of Census \& Statistics, available at http://www.statistics.gov.lk/ (Accessed 09 ${ }^{\text {th }}$ May 2011).

18. WHO. WHO technical meeting on "Housing-Health Indicators" Results of review and data availability screening in Member States. In: Summary report World Health Organization Regional Office for Europe, European Centre for Environment and Health, Bonn Office. Geneva: World Health Organization; 2004.

19. Siritunga T. Effect of air pollution on respiratory health of children in an urban and a rural area in the district of Kandy. MD Thesis, Post Graduate Institute of Medicine, Colombo: University of Colombo; 2006.

20. Fernando $M$, Senathilake $P$, Perera B. Body mass index, allergic rhinitis and asthma in children. Sri Lanka Journal of Child Health. 2004;33:102-5.

21. Samarasinghe A. Prevalence of childhood asthma among 5-11 year old children in an urban setting and its impact on the child and the family. MD Thesis, Post Graduate Institute of Medicine, Colombo: University of Colombo; 2007.

22. Wickremasinghe R, Gunasekara K: International Study of asthma and allergies in childhood (ISAAC Study) In: Proceedings from "Symposium on Respiratory Diseases", Respiratory Disease Study Group - Sri Lanka: 2004; Colombo; 2004

23. Asher MI, Montefort S, Björkstén B, Lai CKW, Strachan DP, Weiland SK, et al. Worldwide time trends in the prevalence of symptoms of asthma, allergic rhinoconjunctivitis, and eczema in childhood: ISAAC Phases One and Three repeat multicountry cross-sectional surveys. Lancet. 2006;368(9537):733-43.

24. Almqvist C, Worm M, Leynaert B, for the working group of GALENWPG. Impact of gender on asthma in childhood and adolescence: a GA2LEN review. Allergy. 2008;63(1):47-57.

25. der Voort AMM S-V, Arends LR, de Jongste JC, Annesi-Maesano I, Arshad SH, Barros $\mathrm{H}$, et al. Preterm birth, infant weight gain, and childhood asthma risk: a meta-analysis of 147,000 European children. J Allergy Clin Immunol. 2013;133(5):1317-29.

26. Abe K, Shapiro-Mendoza CK, Hall LR, Satten GA. Late preterm birth and risk of developing asthma. J Pediatr. 2010;157(1):74-8.

27. Noal RB, Menezes AMB, Macedo SEC, Dumith SC. Childhood body mass index and risk of asthma in adolescence: a systematic review. Obes Rev. 2011;12(2):93-104.

28. Po JYT, FitzGerald JM, Carlsten C. Respiratory disease associated with solid biomass fuel exposure in rural women and children: systematic review and meta-analysis. Thorax. 2011;66(3):232-9.
29. Dharmage SC. Indoor Allergens and Asthma. Australia: Monash University; 2000.

30. Takkouche B, González-Barcala FJ, Etminan M, FitzGerald M. Exposure to furry pets and the risk of asthma and allergic rhinitis: a meta-analysis. Allergy. 2008;63(7):857-64.

31. Bakirtas A. Acute effects of passive smoking on asthma in childhood. Inflamm Allergy Drug Targets. 2009;8(5):353-8.

32. Amarasekera M, Gunawardena NK, de Silva NR, Douglass JA, O'Hehir RE, Weerasinghe A. Impact of helminth infection on childhood allergic diseases in an area in transition from high to low infection burden. Asia Pac Allergy. 2012;2(2):122-8.

33. Senanayake MP, de Silva R, Jayamanna M, Jayasinghe J, Ratnayake D, Jayasuriya $\mathrm{V}$, et al. Identification of aero-allergen sensitization in children seeking treatment for bronchial asthma at a tertiary care hospital for children in Sri Lanka. Ceylon Med J. 2014;59(3):89-93.

\section{Submit your next manuscript to BioMed Central and take full advantage of:}

- Convenient online submission

- Thorough peer review

- No space constraints or color figure charges

- Immediate publication on acceptance

- Inclusion in PubMed, CAS, Scopus and Google Scholar

- Research which is freely available for redistribution 